\title{
Effect of Trehalose Supplementation to Semen Extender on Quality of Cryopreserved Stallion Semen
}

\author{
D. Jhamb ${ }^{1}$, S. Sharma ${ }^{2}$, T. R. Talluri ${ }^{3}$, S. S. Nirwan ${ }^{1 *}$, R. Juneja ${ }^{1}$, V. Kumar ${ }^{1}$,
} A. Tanwar ${ }^{1}$, K. Pargi ${ }^{1}$, Deepak ${ }^{1}$, D. Nandan ${ }^{1}$, P. Kumar ${ }^{2}$, M. Gaur ${ }^{1}$ and L. K. Gautam ${ }^{4}$

${ }^{1}$ Department of Veterinary Gynaecology and Obstetrics, CVAS, Navania, ${ }^{4}$ Department of Animal Breeding and Genetics, CVAS, Navania and ${ }^{2}$ Department of Veterinary Gynaecology and Obstetrics, CVAS, Bikaner and ${ }^{3}$ NRCE, Bikaner

*Corresponding author

\section{A B S T R A C T}

The aim of the present study was to evaluate the cryoprotective effect of trehalose on stallion semen quality like progressive sperm motility, viability, acrosome integrity, membrane integrity. A total of 42 ejaculates from six Marwari stallion (seven ejaculate from each) were used. Immediately after gross evaluation, the

\section{Keywords}

Trehalose, Stallion, Semen, Motility

\section{Article Info}

Accepted:

12 December 2020

Available Online:

10 January 2021 semen was filtered into a pre warm, graduated measuring bottle to get gel free semen and it was diluted with primary extender to get sperm pellets. Secondary extender was added and divided into three equal aliquots served as control, treatment $1(50 \mathrm{mM}$ treahalose $)$ and treatment $2(150 \mathrm{mM}$ trehalose $)$. At post-thaw stage there was reduction in the progressive sperm motility, per cent viability, membrane integrity and acrosome integrity in all three groups. In $\mathrm{T}_{1}$ group per cent progressive sperm motility and viability was higher $(\mathrm{P}<0.05)$ than control. However, in control group percentage hypo-osmotic swollen spermatozoa were lower $(\mathrm{P}<0.05)$ than $\mathrm{T}_{1}$ and $\mathrm{T}_{2}$. In $\mathrm{T}_{1}$ group per cent spermatozoa with intact acrosome was higher $(\mathrm{P}<0.05)$ than control. The deleterious effect of group $\mathrm{T}_{2}$ on acrosome integrity and membrane integrity was significant. In conclusion, addition of $50 \mathrm{mM}$ trehalose improved post-thawing semen quality.

\section{Introduction}

Artificial Insemination (AI) in equine breeding has now been accepted in horse industry. The use of frozen semen AI has increased greatly over last few decades (Kumar, 2008). The use of artificial insemination with frozen semen in equine reproduction has become increasingly popular and several breed registries are approving the foals born from frozen semen (Loomis, 2001).

During cooling and freezing spermatozoa undergo a series of chemical and physical 
changes that include partial dehydration, cryoprotectant penetration of cells, reorganization of membrane lipids and proteins, exposure to high salt concentrations and exposure to inter and intracellular ice crystals. Cryopreservation protocols are designed to minimize the negative effects of these stresses (Loomis and Squires, 2005).

Various degrees of damage to sperm occur during freezing and thawing including perturbations to the sperm organelles and change in membrane fluidity and enzymatic activity that result in reduction in sperm motility, viability and freezing ability (Alvarez and Storey, 1983). Oxidative damage is a major factor in sperm cryodamage (Ghallab et al., 2017). There is increase in ROS production and decrease in antioxidants levels during sperm cryopreservation, which causes increase in susceptibility of frozen thawed to lipid peroxidation (Aitken and Krausz, 2001). Lipid peroxidation is associated with premature aging and DNA fragmentation in cryopreserved equine spermatozoa (OrtegaFerrusola et al., 2008). The semen quality can be improved by preventing sperm cryoinjury during cooling and freezing process by addition of antioxidants in the semen extender.

Trehalose is a non permeating disaccharide which acts as non enzymatic scavenger. Through its osmotic effects trehalose induces its protective effects against oxidative damage rendering a role in protection of spermatozoa against ROS (Reddy et al., 2010). Trehalose also act as hypertonic media causing cellular osmotic dehydration before freezing and decreasing the amount of cell injury by crystallization (Bucak et al., 2007).

Trehalose supplementation in semen extender has potential to improve the overall quality and freezing ability of semen in different farm animals including stallion. The present study was designed to investigate the effect of trehalose supplementation on post thaw quality of Marwari horse stallion.

\section{Materials and Methods}

The study was carried out in the animal reproduction laboratory of equine production campus (EPC), ICAR- National Research Centre on Equine (NRCE) Bikaner. Six adult Marwari stallions managed under uniform conditions of feeding and management were used for the present study.

\section{Preparation of primary extender}

Primary extender was prepared by adding $0.15 \mathrm{~g}$ glucose, $2.6 \mathrm{~g}$ sodium citrate dehydrate, $0.37 \mathrm{~g}$ di-sodium EDTA, $0.12 \mathrm{~g}$ sodbicarbonate, $0.10 \mathrm{~g}$ Streptomycin and 50000100000 unit Benzyl penicillin in distilled water to make $100 \mathrm{ml}$ as described previously (Ravi, 2014).

\section{Preparation of secondary extender}

Solution A + Solution B + egg yolk + cryoprotectant

Solution A (EDTA-glucose) was prepared by adding Glucose $6.00 \mathrm{~g}$, Sodium citrate dehydrates $0.37 \mathrm{~g}$, Di-sodium EDTA $0.37 \mathrm{~g}$, Sod-bicarbonate $0.12 \mathrm{~g}$, Streptomycin $0.10 \mathrm{~g}$, Benzyl penicillin $0.10 \mathrm{~g}$. Above all ingredients were dissolved in conical flask with addition of double distilled water and the final volume was made up to $100 \mathrm{ml}$.

Solution B (Lactose) was prepared by adding Lactose $11.00 \mathrm{~g}$, Streptomycin 0.08g, Benzyl penicillin 0. 08g. in a conical flask with addition of double distilled water and the final volume was made up to $100 \mathrm{ml}$ as per Ravi, 2014. 
Solution A $50 \mathrm{ml}$, Solution B 100ml and egg yolk $40 \mathrm{ml}$ was mixed and centrifuged at 3000 RPM $\left(10^{\circ} \mathrm{C}\right)$ for $30 \mathrm{~min}$. The supernatant was filtered through a sterile gauge to prepare the final extender, DMF was added as cryoprotectant at rate of 5\% to the total volume.

\section{Semen collection, evaluation and freezing and post thaw evaluation}

Semen from Six Marwari stallions were collected twice a week during morning hours using Colorado type artificial vagina and a mare in estrus as dummy. Seven ejaculates were collected each from all six stallions. Total Forty two ejaculates were collected. Each ejaculate was filtered through a sterile piece of gauge to measure the gel free semen volume.

Total ejaculate volume and gel free volume were recorded immediately after collection as per standard methods described previously (Kumar, 2017).

The gel free semen was evaluated for progressive sperm motility by CASA (Kumar, 2019), sperm concentration (Kant, 2016), live sperm count (Pintado et al., 2000), membrane integrity (Nie and Wenzel, 2001) and acrosomal integrity (Watson, 1975).

Primary extender in the proportion equal to volume of gel free semen taken into centrifuge tube, subjected to centrifugation (1700-1800 rpm for $3 \mathrm{~min}$ ) to get a sperm pellet at the base after discarding the supernatant.

The sperm pellet which was added with secondary extender containing additives as described below to get a final concentration $150 \times 10^{6}$ spermtaozoa/ml.

The supplementation of additives to the secondary extender was as follows.
Control: Secondary extender (SE) without any additives

Treatment 1: SE with trehalose at $50 \mathrm{mM}$ concentration

Treatment 2: SE with trehalose at $150 \mathrm{mM}$ concentration

Extended semen samples of all the above three aliquots were filled and sealed in $0.5 \mathrm{ml}$ French medium straws of different colors and was sealed with automatic filling and sealing machine, then kept for $2 \mathrm{hr}$ equilibration at $4^{\circ} \mathrm{C}$. Following equilibration, the semen was frozen by vapour freeze technique (Pal et al., 2011) and the straws containing frozen semen were stored in goblets and kept immersed in liquid nitrogen cryocans.

After more than 24 hours of cryopreservation or storage semen straws were taken out and thawed at $37^{\circ} \mathrm{C}$ for 30 seconds. Control, $\mathrm{T}_{1}$ and $\mathrm{T}_{2}$ groups were evaluated for post thaw motility, viability, membrane integrity and acrosome integrity as done for fresh semen.

\section{Evaluation of progressive sperm motility}

Evaluation of progressive sperm motility was done as per Kumar, 2019 with minor modifications. CASA system (HTB CEROS II, Version 1.3, Hamilton Thorne Research, Beverly, MA, USA, Plate 20) equipped with a thermo stage (MiniTherm ${ }^{\circledR}$, Hamilton Thorne Inc. Beverly, MA, USA, Plate 21) was used to analyse the progressive sperm motility. Semen sample ( $4 \mu$ ldiluted aliquots; $50 \mu$ of semen sample dissolved in $1 \mathrm{ml}$ of sodium citrate diluting fluid to make a 1:20 dilution) was loaded in disposable chambers with a 20 $\mu \mathrm{m}$ chamber depth (Leja ${ }^{\circledR}$ Standard Count 8 Chamber Slide, $20 \mu \mathrm{m}$, Leja ${ }^{\circledR}$ Products B.V., Netherlands). For each evaluation, seven microscopic fields, each including at least 250 cells, were analysed. CASA settings used were progressive STR (\%) 50, Progressive VAP $(\mu \mathrm{m} / \mathrm{s}) 37$. System was set to measure 
30 frames per field at frame rate of $60 \mathrm{~Hz}$. Sperm track with a straightness value more than $50 \%$ and velocity average path more than $37 \mu \mathrm{m} / \mathrm{s}$ were progressive motile. Stage temperature was $38^{\circ} \mathrm{C}$.

\section{Evaluation of Sperm concentration}

The sperm concentration, in semen sample mixed with diluting sample (1:20) was estimated by hemocytometer according to Kant, 2016.

\section{Evaluation of live sperm count}

For live sperm count propidium iodide staining procedure given by (Pintado et al., 2000) was used. A stock solution of $0.5 \mathrm{mg}$ propidium iodide per $\mathrm{ml}$ water was prepared, aliquoted and stored frozen at $-20^{\circ} \mathrm{C}$ in the dark. Spermatozoa were diluted in the saline medium and the propidium iodide stock solution was added, so that the final concentration was $5 \mu \mathrm{g} / \mathrm{ml}$. The suspension was incubated for $5 \mathrm{~min}$ at room temperature and spermatozoa were immobilized with formaldehyde $0.003 \%(\mathrm{w} / \mathrm{v})$, BSA (5 $\mu$ l of $100 \mathrm{mg} / \mathrm{ml}$ ) was added and stained samples were placed between a slide and coverslip. Spermatozoa were examined under phasecontrast optics and using the filter for propidium iodide (Fig.2).

\section{Evaluation of membrane integrity}

The procedure described by Nie and Wenzel, 2001 was used to determine the percentage of hypo-osmotic stress test-positive cells in each sample. A $1 \mu \mathrm{L}$ aliquot of each semen sample was mixed in $1.0 \mathrm{~mL}$ of a prewarmed 100 mOsm sucrose solution (1.712 $\mathrm{g}$ sucrose dissolved in $50 \mathrm{~mL}$ of sterile, deionized water). The mixture was incubated at $37^{0} \mathrm{C}$ for 60 minutes in a $1.5-\mathrm{mL}$ microcentrifuge tube. Following incubation, a small drop of sample was placed on a microscope slide and cover slipped for examination by using phasecontrast microscopy (400) to evaluate 100 spermatozoa for evidence of swelling and curling changes.

\section{Evaluation of Acrosomal integrity test}

The acrosome integrity of the sperms was determined by Giemsa stain as per method described by Watson (1975) was followed.

\section{Results and Discussion}

Overall mean total ejaculate volume, overall mean gel volume and overall mean gel free semen volume recorded for fresh semen were $49.47 \pm 5.31 \mathrm{ml}, 18 \pm 3.9 \mathrm{ml}$ and $31 \pm 2.04 \mathrm{ml}$ respectively. Overall mean progressive sperm motility recorded was $76.34 \pm 0.95 \%$. Overall mean sperm concentration was $143.49 \pm 8.29$ millions per ml. Overall mean sperm viability, membrane integrity and acrosome integrity recorded were $85.00 \pm 0.87 \%$. $58.1 \pm 0.86 \%$. $86.97 \pm 0.76 \%$, respectively.

At post-thaw stage there was reduction in the progressive sperm motility in all three groups. In $T_{1}$ group per cent progressive sperm motility was significantly $(\mathrm{P}<0.05)$ higher than control (Table.1). The percentage reduction in progressive sperm motility from fresh to post-thaw stage was 44.31, 28.26 and 46.80 in $\mathrm{C}, \mathrm{T}_{1}$ and $\mathrm{T}_{2}$ group respectively, indicating beneficial effect of $50 \mathrm{mM}$ trehalose.

El Badry et al., 2017 reported improved motility rate of post-thaw stallion spermatozoa frozen by $50 \mathrm{mM}$ trehalose, while higher concentrations $(100 \mathrm{mM}$ and 200 $\mathrm{mM})$ reduced post-thaw motility. Ghallab et al., (2017) reported beneficial effect of 150 $\mathrm{mM}$ trehalose on motility post thaw stallion spermatozoa. Vafaei et al., (2019) reported toxic effect of $150 \mathrm{mM}$ trehalose on motility of post thaw stallion spermatozoa. 
Similarly beneficial effect of different concentrations of trehalose supplementation for different species has been reported. Aisen et al., 2002 (Ram, 100mOsm), Bucak et al., 2007 (Ram, 50mM), Matsuoka et al., 2006 (Ram, 435mM), Hu et al., 2009 (Boar, 25,50,100 and 200mM), Reddy et al., 2010 (Buffalo, 100mM), Ozturk et al., 2017 (Bull, $25 \mathrm{mM})$ and Bittencourt et al., 2018 (Ram,100mOsm).While deleterious effect of trehalose has also been reported by Aisen $e t$ al., 2002 (Ram, 200mOsm).

At post-thaw stage there was reduction in the per cent viable sperm in all three groups(Table.1). In $\mathrm{T}_{1}$ group per cent viable sperm was significantly $(\mathrm{P}<0.05)$ higher than control. The percentage decease in per cent viable sperm from fresh to post-thaw stage was $43.4,29.74$ and 43.81 in $\mathrm{C}, \mathrm{T}_{1}$ and $\mathrm{T}_{2}$ group respectively, pointing to advantageous effect of $50 \mathrm{mM}$ trehalose.

El Badry et al., 2017 reported that $25 \mathrm{mM}$ and $50 \mathrm{mM}$ trehalose improved viability of postthaw stallion spermatozoa but $200 \mathrm{mM}$ proved to be deleterious. Ghallab et al., 2017 also reported beneficial effect of $150 \mathrm{mM}$ trehalose on viability of post thaw stallion spermatozoa. Vafaei et al., 2019 reported toxic effect of $150 \mathrm{mM}$ trehalose on motility of post thaw stallion spermatozoa. Similarly, beneficial effect of different concentrations of trehalose supplementation on post-thaw viability for different species has been reported. Matsuoka et al., 2006 (Ram, 435mM), Reddy et al., 2010 (Buffalo, 100mM), El Badry et al., 2017 (Equine $50 \mathrm{mM}$ and $25 \mathrm{mM}$ ), Ozturk et al., 2017 (Bull, 25mM). Bittencourt et al., 2018 (Ram, 100mOsm).

At post-thaw stage there was reduction in the per cent hypo-osmotic swollen spermatozoa in all three groups. However, in control group per cent hypo-osmotic swollen spermatozoa were significantly $(\mathrm{P}<0.05)$ lower than $\mathrm{T}_{1}$ and $\mathrm{T}_{2}$ (Table.1). The deleterious effect of group $\mathrm{T}_{2}$ on percentage hypo-osmotic swollen spermatozoa was significant. The percentage decease in per cent hypo-osmotic swollen spermatozoa from fresh to post-thaw stage was $43.81,31.81$ and 47.25 in $\mathrm{C}, \mathrm{T}_{1}$ and $\mathrm{T}_{2}$ group, respectively supporting supplementation of low dose of trehalose.

In concord with our results beneficial effect of $50 \mathrm{mM}$ and $100 \mathrm{mM}$ trehalose on membrane integrity has been reported by El Badry et al., 2017 for post-thaw equine semen and deleterious effect observed on $200 \mathrm{mM}$ trehalose. Ghallab et al., 2017 reported beneficial effect of $100 \mathrm{mM}$ and $150 \mathrm{mM}$ trehalose on membrane integrity on post thaw stallion spermatozoa. In agreement with our finding, Aisen et al., 2002 (Ram, 100mOsm), Matsuoka et al., 2006 (Ram, 435mM), Hu et al., 2009 (Boar, 25,50,100 and 200 $\mathrm{mmol} / \mathrm{liter}$ ), Reddy et al., 2010 (Buffalo, $100 \mathrm{mM}$ ) beneficial effect of trehalose has been reported. Contrary to present study no significant beneficial effect was reported by Bucak et al., 2007 (Ram, 100mM).

At post-thaw stage there was reduction in the per cent spermatozoa with intact acrosome in all three groups. In $\mathrm{T}_{1}$ group per cent spermatozoa with intact acrosome was significantly $(\mathrm{P}<0.05)$ higher than control (Table.1).

The deleterious effect of group $\mathrm{T}_{2}$ on acrosome integrity was significant. The percentage decease in per cent intact acrosome spermatozoa from fresh to postthaw stage was $16.21,11.6$ and 19.32 in $\mathrm{C}, \mathrm{T}_{1}$ and $\mathrm{T}_{2}$ group respectively, demonstrating beneficial effect of $50 \mathrm{mM}$ trehalose.

In concord with our results beneficial effect of $50 \mathrm{mM}$ and $100 \mathrm{mM}$ trehalose on acrosome integrity has been reported by El Badry et al., 
2017 for post-thaw equine semen while deleterious effect on acrosome integrity by 200mM trehalose. However, Ghallab et al., 2017 reported improved acrosome integrity using $75 \mathrm{mM}, 100 \mathrm{mM}$ and $150 \mathrm{mM}$ trehalose. Similarly, beneficial effect of trehalose has been reported by Aisen et al., 2002 (Ram, 100mOsm improved), Hu et al., 2009 (Boar, 25,50,100 and $200 \mathrm{mmol} /$ liter) and Reddy et al., 2010 (Buffalo, 100mM)
Contrary to our finding, Bucak et al., 2007 reported no improvement in post-thaw acrosome integrity by $50 \mathrm{mM}$ and $100 \mathrm{mM}$ trehalose on ram semen, like wise Bittencourt et al., 2018 (Ram, 100mOsm) and Ozturk et al., 2017 (Bull, 25mM) reported no significant benefit on acrosome integrity postthaw while harmful effects of trehalose has been reported by Aisen et al., 2002 (Ram, 200mOsm).

Table.1 Progressive motility, viability, membrane integrity and acrosome integrity in post-thaw semen of stallions treated with different concentrations of trehalose

\begin{tabular}{|l|l|l|l|l|}
\hline Group & \multicolumn{4}{|c|}{ Post-thaw parameters } \\
\cline { 2 - 5 } & $\begin{array}{l}\text { Progressive } \\
\text { sperm motility } \\
(\%)\end{array}$ & Viability (\%) & $\begin{array}{l}\text { Membrane integrity } \\
(\%)\end{array}$ & Acrosome integrity (\%) \\
\hline $\mathbf{C}$ & $42.51^{\mathrm{a}} \pm 0.98$ & $48.36^{\mathrm{a}} \pm 0.89$ & $32.65^{\mathrm{b}} \pm 0.43$ & $72.87^{\mathrm{b}} \pm 0.50$ \\
\hline $\mathbf{T}_{1}$ & $54.76^{\mathrm{b}} \pm 1.11$ & $60.03^{\mathrm{c}} \pm 1.28$ & $39.62^{\mathrm{d}} \pm 0.61$ & $76.89^{\mathrm{d}} \pm 0.49$ \\
\hline $\mathbf{T}_{\mathbf{2}}$ & $40.61^{\mathrm{a}} \pm 0.98$ & $48.01^{\mathrm{a}} \pm 1.00$ & $30.65^{\mathrm{a}} \pm 0.45$ & $70.16^{\mathrm{a}} \pm 0.46$ \\
\hline
\end{tabular}

Mean values with different superscripts between treatment groups differ significantly $(\mathrm{P}<0.05)$. Group $\mathrm{C}, \mathrm{T}_{1}, \mathrm{~T}_{2}$, contain $0 \mathrm{mM}$ trehalose, $50 \mathrm{mM}$ trehalose and $150 \mathrm{mM}$ trehalose respectively.

Fig.1 Semen collection by Colorado model Artificial vagina

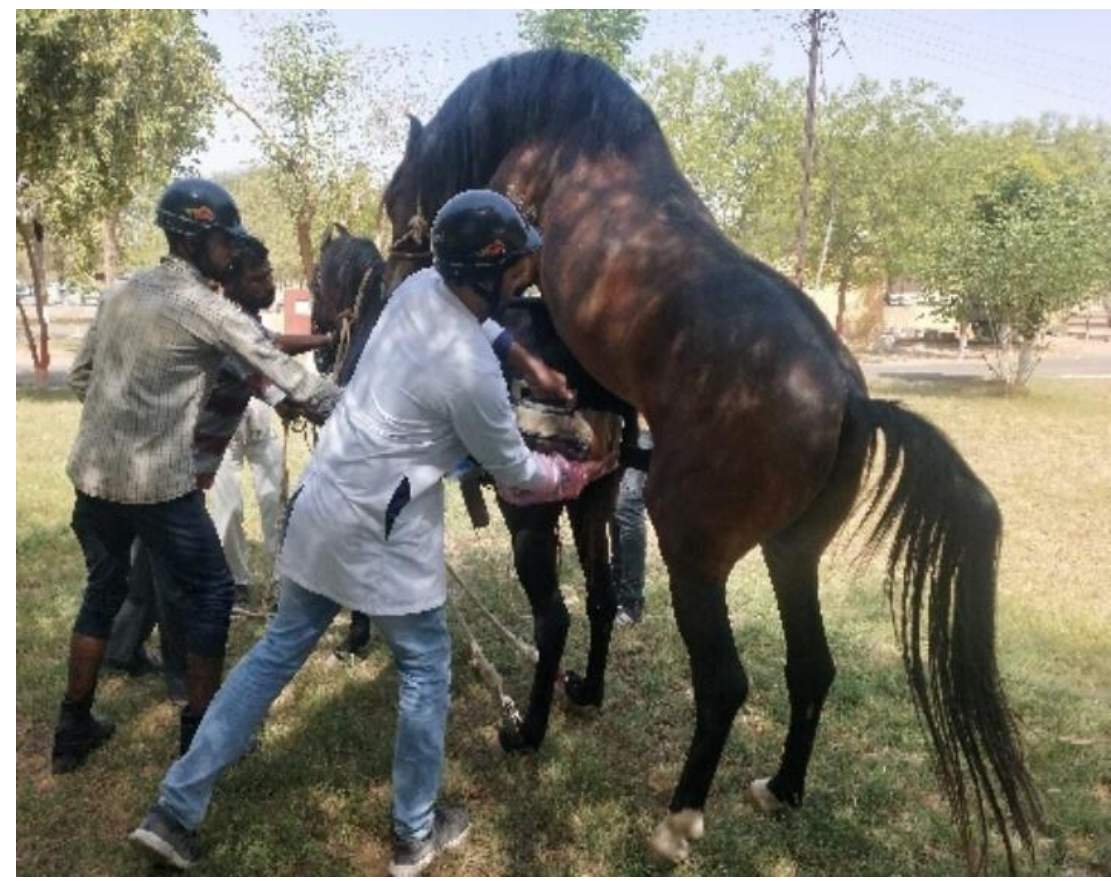


Fig.2 Sperm viability examination using filter for propidium iodide (left) and under phase contrast optics (right)

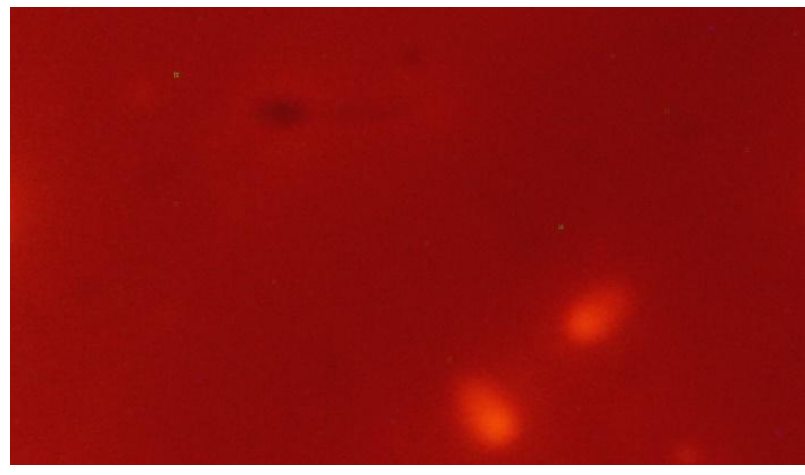

Trehalose exert cryoprotective role by decreasing intracellular ice crystal formation, thus maintaining the osmotic balance of the diluent (Garde et al., 2008). Trehalose is a non-penetrating disaccharide, which has a protective action on cells both by increasing the tonicity of the extender and by stabilising the plasma membrane, possibly due to specific interactions with head groups of membrane phospholipids (Crowe et al., 1987). Trehalose inserts itself into the membrane phospholipids bilayer, thus modulating membrane fluidity and therefore rendering the membrane more stable during freezing (Aboagla and Terada, 2003).

Trehalose is a non permeating disaccharide which acts as non enzymatic scavenger. Through its osmotic effects trehalose induces its protective effects against oxidative damage rendering a role in protection of spermatozoa against ROS (Reddy et al., 2010). Trehalose also act as hypertonic media causing cellular osmotic dehydration before freezing and decreasing the amount of cell injury by crystallization (Bucak et al., 2007). Difference may be ascribed to individual variation in stallion spermatozoa, breeds, type of diluents used in each study (Ghallab et al., 2017). Deleterious effect on sperms by high concentration of trehalose might be due to the incompatibility between water efflux and cellular integrity, further the variable results of reported studies might be due to different extender compositions used or different species exhibiting different tolerance level for trehalose (Ahmad and Aksoy, 2012).

Further study is required regarding fertility of semen frozen by supplementing freezing media by trehalose.

\section{Conflict of interest}

The authors have no conflict of interest.

\section{Acknowledgements}

We are thankful to Dean, College of Veterinary and Animal Science, Navania, Udaipur, Rajasthan, India and Incharge, NRCE, Bikaner for allowance of this research work and provision of necessary funding.

\section{References}

Aboagla, E. M. E. and Terada, T. 2003. Trehalose-enhanced fluidity of the goat sperm membrane and its protection during freezing. Biology Reproduction. 69:1245-1250.

Ahmad and Aksoy. 2012. Trehalose as a Cryoprotective Agent for the Sperm Cells: A Mini Review. Animal Health, Production and Hygiene. 1(2):123-129.

Aisen, E. G., Mesina, V. H. and Ventruino, A. 
2002. Cryopreservation and post thaw fertility of ram semen frozen in different trehalose concentration. Theriogenology. 57:1801-1808.

Aitken, R. J. and Krausz, C. 2001. Oxidative stress, DNA damage and $\mathrm{Y}$ chromosome. Reproduction. 122(4):497-506.

Alvarez, J. G. and Storey, B. T. 1983. Taurine, Hypotaurine, epinephrine and albumin inhibit lipid peroxidation in rabbit spermatozoa and protect against loss of motility. Biology Reproduction. 29:548-555.

Bittencourta, R. F., Obab, E,. De Almeida Biscardea, C. E., Azevedoc, H. C., Bittencourta, M. V., De Menezesa, G. F. O., Da Silva Limaa, A., Da Mata Fuchsa, K., De Lisboa Ribeiro Filho, A. 2018. Dimethylacetamide and trehalose for ram semen cryopreservation. Cryobiology. 85:1-6.

Bucak, M. N., Atessahin, A., Varisili, O., Yuce, A., Tekin, N. and Akcay, A. 2007. The influence of trehalose, taurine, cysteamine and hyaluronan on ram semen: microscopic and oxidative stress parameters after the freezethawing process. Theriogenology. 67:1060-1067.

Crowe, J. H., Crowe, L. M., Carpenter, J. F. And Aurell Wistrom, C. 1987. Stabilization of dry phospholipid bilayers and proteins by sugars. Biochemical Journal. 242: 1-10.

El Badry, D. A., El-Maaty, A. M. A. and ElSisy, G. A. 2017. The Effect of trehalose supplementation of INRA-82 extender on quality and fertility of cooled and frozen-thawed Stallion spermatozoa. Journal of Equine Veterinary Science. 48:86-92.

Garde, J. J., Del, O. A., Soler, A. J., Espeso, G., Gomendio, M. and Roldan, E. R. S. 2008. Effect of egg yolk, cryoprotectant, and various sugars on semen cryopreservation in endangered Cuvier's gazelle (Gazella cuvieri). Animal Reproduction Science.108:384401.

Ghallab, A. M., Shahat, A. M., Fadi, A. M., Ayoub, M. M. and Moawad, A. R. 2017. Impact of supplementation of semen extender with antioxidants on the quality of chilled or cryopreserved Arabian stallion spermatozoa. Cryobiology.79:17-20.

Hu, J. H., Li, Q. W., Li, G., Jiang, Z. L., Bu, S. H., Yang, H. and Wang, L. Q. 2009. The cryoprotective effect of trehalose supplementation on boar spermatozoa quality. Animal Reproduction Science.112:107-18.

Kant, S. 2016. Effect of caffeine as an additive in semen extender to improve frozen thawed semen quality of Marwari horses and exotic donkeys. MVSc. Thesis submitted to Indian Veterinary Research Institute. Barielly.

Kumar, D. 2008. Studies on cryopreservation of equine semen. Thesis submitted to UP Pandit Deen Dayal Upadhyaya Pashu Chikitsa Vigyan Vishwavidhalya Evam Go Anusandhan Sansthan, Mathura.

Kumar, P. 2017. Effect of ascorbic acid and glutathione on prefreeze and post thaw quality of equine semen. MVSc. Thesis submitted to Rajasthan University of Veterinary and Animal Science, Bikaner.

Kumar, P. 2019. Effect of addition of cholesterol-loaded cyclodextrin on quality of semen in Marwari horse and Poitou donkey. PhD thesis, Rajasthan University of Veterinary and Animal Science, Bikaner, Rajasthan.

Loomis, P. R. and Squires, E. L. 2005. Frozen semen management in equine breeding programs. Theriogenology. 64:480-491.

Loomis, P. R., 2001. Recent advances in the equine frozen semen industry. In 
proceedings of 3rd international symposium on stallion reproduction, Colorado State University, Fort Collins, USA. 18.

Matsuoka T, Imai H, Kohno K and Fukui Y. 2006. Effects of bovine serum albumin and trehalose in semen dilutents for improvement of frozen thawed ram spermatozoa. Journal of Reproduction and Development. 52(5):657-683.

Nie, G. J. and Wenzel, J. G. W. 2001. Adaptation of the hypo-osmotic swelling test to assess functional integrity of stallion spermatozoal plasma membranes. Theriogenology. 55:1005-18.

Ortega- Ferrusola, C., Sotillo- Galan, Y., Varela- Fernandez, E., Gallardo- Bolanos, J. M., Muriel, A., Gonzalez- Fernandez, L., and Pena, F. J. 2008. Detection of "apoptosis- like" changes during the cryopreservation process in equine sperm. Journal of andrology. 29(2): 213-221.

Ozturk , C., Gungor, S., Ataman, M. B. and 1li, P. 2017. Effects of arginine and trehalose on post-thawed bovine sperm quality. Acta Vet Hungarica. 65(3):429439.

Pal, Y., Arangasamy, A., Legha, R. A., Singh, J., Bansal, R. S., Khurana, S. K. and Tandon, S.N. 2011. Freezability and fertility of Marwari stallion semen. Indian Journal of Animal Science. 81(5): 445-447.

Pintado, B., Fuente de la, J. and Roldan, E. R.
S. 2000. Permeability of boar and bull spermatozoa to the nucleic acid stains propidium iodide or Hoechst 33258, or to eosin: accuracy in the assessment of cell viability. Journal of Reproduction Fertility.118:145-152.

Ravi, S. K. 2014. Effect of dietary n-3 PUFA on ovarian function, embryonic development and semen quality in Marwari horses. PhD. Thesis submitted to Indian Veterinary Research Institute, Izatnagar, U.P.

Reddy, N. S. S., Mohanarao, G. J., and Atreja, S. K. 2010. Effects of adding taurine and trehalose to a tris based egg yolk extender on buffalo (Bubalus bubalis) sperm quality following cryopreservation. Animal Reproduction Science.119:183-190.

Soni, Y. 2016. Study of cryopreservation of stallion semen using glycerol and dimethylformamide cryoprotectants. PG thesis. Rajasthan University of Veterinary and Animal Science. Bikaner. Rajasthan.

Vafaei, F., Kohram, H., Zareh-Shahne, A., Ahmad, E. And Seifi-Jamadi, A. 2019. Influence of Different Combinations of Permeable and Nonpermeable Cryoprotectants on the Freezing Capacity of Equine Sperm. Journal of Equine Veterinary Science. 75:69e-73.

Watson, P. F. 1975. Use of giemsa stain to detect change in acrosome of frozen ram spermatozoa. Veterinary Record. 97:12-15.

\section{How to cite this article:}

Jhamb, D., S. Sharma, T. R. Talluri, S. S. Nirwan, R. Juneja, V. Kumar, A. Tanwar, K. Pargi, Deepak, D. Nandan, P. Kumar, M. Gaur and Gautam, L. K. 2021. Effect of Trehalose Supplementation to Semen Extender on Quality of Cryopreserved Stallion Semen. Int.J.Curr.Microbiol.App.Sci. 10(01): 1342-1350. doi: https://doi.org/10.20546/ijcmas.2021.1001.160 